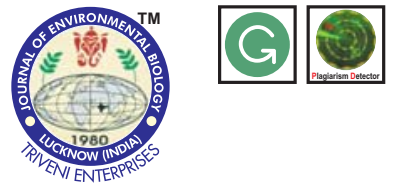

\title{
Comparative effect of formulated kairomonal dusts on parasitization efficiency of Trichogramma spp.
}

Authors Info

M. Srivastava ${ }^{1 *}$, A.K. Singh ${ }^{2}$, S.G. Parihar ${ }^{3}$, R.D. Gautam ${ }^{4}$ and Veereshkumar ${ }^{5}$

${ }^{1}$ Division of Entomology, Indian Agricultural Research Institute, New Delhi-110 012, India

'Department of Zoology, Delhi University, Delhi-110 007, India

${ }^{3}$ Department of Zoology, Hans Raj College, Delhi University,

Delhi-110 007, India

${ }^{4}$ Department of Entomology, Indian Agricultural Research Institute, New Delhi-110 012, India

${ }^{5}$ Department of System Research, ICAR-Central Agroforestry Research Institute, Jhansi-284003, India

${ }^{*}$ Corresponding Author Email : madhulika.csir@gmail.com

Key words

China clay,

Kairomone,

Phytophagus insects,

Parasitoid activity,

Trichogramma spp.

Publication Info

Paper received : 08.03.2016

Revised received : 11.07.2016

Re-revised received : 14.12 .2016

Accepted :22.12.2016
Abstract

Aim: A number of chemicals released by phytophagous insects and plants serve as cues for their natural enemies. Egg parasitoid Trichogramma respond towards chemical cues present in the environment for locating their hosts. Formulations are the end user product for pest control because it contains the active ingredient present in it. The main objective of the present study was to understand the effect of different concentrations of kairomones and different clays on various Trichogramma spp.

Methodology: The nucleus culture of the host insect used in the present study was maintained on the eggs of rice meal moth Corcyra cephalonica on crushed sorghum grains. Culture of the parasitoid was maintained in glass vials of $10 \times 2.5 \mathrm{~cm}$ size at $25 \pm 1{ }^{\circ} \mathrm{C}$ and $65 \pm 5 \% \mathrm{RH}$ in a culture room on UV sterilized, $0-24 \mathrm{hr}$ old $\mathrm{C}$. cephlonica eggs. Twenty different combinations of three straight chain saturated hydrocarbons (Pentacosane, Docosane and Tricosane) used in three different combinations viz., $125 \mathrm{ng} \mathrm{cm}^{-2}\left(\mathrm{C}_{1}\right), 250 \mathrm{ng}$ $\mathrm{cm}^{-2}\left(\mathrm{C}_{2}\right)$ and $375 \mathrm{ng} \mathrm{cm}^{-2}\left(\mathrm{C}_{3}\right)$, designated as 1,2 and 3 were tested for their kairomonal response. Three different concentrations of each synthetic kairomone was prepared with HPLC grade hexane. Five kaiomonal dust formulations were prepared using three different clays viz; kailonite, china clay and fuller's earth.

Results: Trichogramma achaeae resulted in highest value of PAI (7.19) with kailonite clay, whereas china clay showed highest value of parasitism $(9.79 \%)$ and emergence $(9.79 \%)$ with T. brasiliensis. Mean PAl ranged between 2.02 to 7.19 irrespective of Trichogramma spp. Maximum parasitization (9.96\%) was observed in case of $T$. japonicum as against lowest in T. chilonis $(6.48 \%)$ on kaolinite clay. Similarly, maximum adult emergence $(7.42 \%)$ in T.japonicum was recorded as against lowest in T. chilonis (5.15\%) on kailonite clay.

Interpretation: Natural enemies including egg parasitoid like T. chilonis respond towards chemical cues present in the environment to locate their hosts. Many a times these cues are associated with host and host by product itself. Therefore, it was found that the emission rate of synthetic kairomone was fastest from kailonite clay as compared to china clay and fuller's earth. $T$. achaeae resulted in the highest value of PAI (7.19) with kailonite clay, whereas china clay showed the highest value of parasitism (9.79\%) and emergence (9.79 $\%$ ) with $T$. brasiliensis. T. brasiliensis and $T$. japonicum with kairomonal formulation (Tricosane @0.0001 g $10 \mathrm{ml}^{-1}$ ) and kailonite clay were found to be the best combination for any integrated pest management programm.

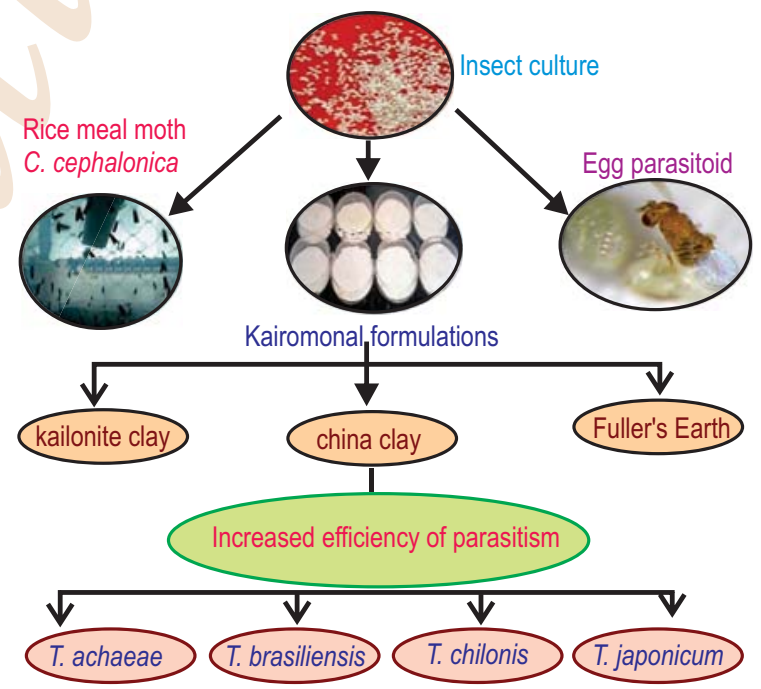




\section{Introduction}

Success of natural enemies, particularly well recognized egg parasitoid, Trichogrammatid (Gautam, 1994; Rahman et al., 2003; Balakrishnan et al., 2004) in pest management depends upon its host acceptance and searching efficiency in a highly complex crop environment due to release of several volatile compounds termed as allelochemicals (synomones and kairomones). Kairomone is a chemical substance emitted by an organism and detected by another of a different species which gains advantage from this, e.g a parasitoid seeking a host. Kairomones, derived from hosts plays a key role in increasing efficiency of natural enemies. Basically, these are present in the body wash, scales, saliva and excreta of an organism. The kairomones from $C$. cephalonica adult moth could stimulate the searching behavior of Trichogramma adult. Tricosane, Pentacosane hexacosane, docosane and nonacosane, the components of the scales of lepidopteron moths increased the parasitizing efficiency of Trichogrammatids (Padmavathi and Paul, 1998; Paul et al., 2008). The use of a mixture with heneicosane, tricosane, pentacosane, heptacosane and nonacosane increased the upwind regression in the case of $T$. brassicae Bezdeko (Renou et al., 1992).

Tondon (2001) highlighted future prospects of kairomones in enhancing the efficiency of natural enemies for the success of biological control of crop pests. Modifying insect behavior in pest management programs through utilization of non-toxic semiochemicals is recognized as a promising alternative to conventional approaches. Foraging entomophages use chemical cues extensively to locate, identify and exploit their hosts as these elicit stimulants from their body (cuticle, excreta and saliva) (Fatouros et al., 2008; Colazza et al., 2010; Colazza et al., 2014 ). Since the host endeavors to be as inconspicuous as possible, indirect cues to its location are often the only information available to the foraging parasitoid female. The development of efficacious and environmentally acceptable technique for the control of insect pests has received considerable research effort. An appealing potential component of a pest management strategy is the enhancement of activity of insect natural enemies through permeation of the atmosphere with semiochemicals released by the host plants (synomones), as well as kairomones.

Dust formulations can be more effective because the effect of weathering on the release rate would be less than that occurring under field situations (Caro et al., 1981; Jackson et al., 2005). It may be noted that the pesticide formulation is a physical mixture of one or more biologically active chemicals and inert ingredients, which provide effective and economical control of the pests, while kairomonal formulation is aimed to enhance the parasitism or predation capacity of a target natural enemy. Long back, the evidence of kairomonal activity present in the hexane body wash of rice meal moth, $C$. cephalonica has been identified. However, concerted efforts on the application aspects of kairomones, especially development of suitable kairomonal formulation against Trichogramma spp. is extremely scanty. Therefore, the main objective of the present study was to understand the effect of different concentrations of kairomones and different clays on various Trichogramma spp.

\section{Materials and Methods}

Insect cultures: The nucleus culture of the host insect used in the present study was maintained on the eggs of the rice meal moth, C. cephalonica obtained from Mass Production Laboratory, Division of Entomology, Indian Agricultural Research Institute (Pusa), New Delhi, on crushed sorghum grains as described by Paul and Sreekumar (1998). Culture of the parasitoid was maintained in glass vials of $10 \times 2.5 \mathrm{~cm}$ size at $25 \pm 1^{\circ} \mathrm{C}$ and $65 \pm 5 \%$ relative humidity in a culture room on UV sterilized, $0-24 \mathrm{hr}$ old $C$. cephalonica eggs following the method by Gautam (1994).

Preparation of different formulations of saturated hydrocarbons: Twenty different combinations of three straight chain saturated hydrocarbons, Pentacosane, Docosane and Tricosane used in three different combinations viz., $125 \mathrm{ng} \mathrm{cm}^{-2}$ $\left(C_{1}\right), 250 \mathrm{ng} \mathrm{cm}^{-2}\left(C_{2}\right)$ and $375 \mathrm{ng} \mathrm{cm}^{-2}\left(C_{3}\right)$ designated 1,2 and 3 were tested for their kairomonal response. Three different concentrations of each synthetic kairomone were prepared using HPLC grade hexane and mixed in equal amount to make 20 different combinations.

Bioassay studies: Bioassay studies were carried out under laboratory conditions at $26 \pm 2^{\circ} \mathrm{C}$ and $65 \pm 5 \% \mathrm{RH}$, using glass petridishes of size $150 \times 15 \mathrm{~mm}$ size as the arena, the base of which was covered with a Whatman No1 filter paper of $2 \times 2 \mathrm{~cm}$ size. Thirty such eggs were pasted equidistantly on each egg card and the extracts of different concentrations were applied on five such egg cards @ 50 $\mu$ l. These five cards along with one control card treated with hexane were arranged equi-distantly in the experimental arena of $150 \mathrm{~mm}$ diameter petridish. In each petridish, ten healthy, 0-24 hr old, anesthetized and fast reviving females of $T$. chilonis were released at the centre. The parasitoids were allowed to search in the experimental arena for a total period of $45 \mathrm{~min}$ from the time of recovery. Number of parasitoids that visited each egg card was referred as 'Parasitoid Activity Index (PAI)'. The parasitoids were removed carefully after $45 \mathrm{~min}$ from each egg card and were kept individually in homeopathic vials for development at $26 \pm 2^{\circ} \mathrm{C} .0-24 \mathrm{hrs}$ old females of Trichogramma were used for all the experiments carried out in this study.

Five kairomonal dust formulations were prepared using three different clays viz; kailonite, china clay and fuller's earth. A total of three formulations were prepared using hydrocarbons namely Pentacosane, Docosane and Tricosane in three different combinations viz., $125 \mathrm{ng} \mathrm{cm}^{-2}$ (1), $250 \mathrm{ng} \mathrm{cm}^{-2}$ (2) and $375 \mathrm{ng} \mathrm{cm}^{-2}$ (3). Pentacosane, Docosane and Tricosane used in the present studies were obtained from Sigma, U.S.A. These were then 
mixed with appropriate quantity of formulations. Formulated products were abbreviated as $\mathrm{C}_{1}$ (Pentacosane $250 \mathrm{ng} \mathrm{cm}^{-2}$ + Docosane $250 \mathrm{ng} \mathrm{cm}^{-2}+$ Tricosane $250 \mathrm{ng} \mathrm{cm}^{-2}$, or $\mathrm{P}_{2}+\mathrm{D}_{2}+\mathrm{T}_{2}$ ), $\mathrm{C}_{2}$ (Pentacosane $125 \mathrm{ng} \mathrm{cm}^{-2}+$ Docosane $125 \mathrm{ng} \mathrm{cm}^{-2}+$ Tricosane $250 \mathrm{ng} \mathrm{cm}$ or $P_{1}+D_{1}+T_{2}$ ), $C_{3}$ (Pentacosane $375 \mathrm{ng} \mathrm{cm}^{-2}+$ Docosane $250 \mathrm{ng} \mathrm{cm}^{-2}+$ Tricosane $250 \mathrm{ng} \mathrm{cm}^{-2}$ or $\left.\mathrm{P}_{3}+\mathrm{D}_{2}+\mathrm{T}_{2}\right), \mathrm{C}_{4}(\mathrm{C}$. cephalonica scale extract $\left(0.2 \mathrm{~g} \mathrm{10ml}^{-1}\right), \mathrm{C}_{5}($ Tricosane @ $0.0001 \mathrm{~g}$ $10 \mathrm{ml}^{-1}$ ) and $\mathrm{C}_{6}$ (Control - C. cephalonica eggs washed with hexane). These were tested against five species of Trichogramma viz., T. chilonis (Ishii), T. brasiliensis (Ashmead), T. achaeae (Nagarkatti \& Nagaraja), T. exiguum (Pinto, Platner \& Oatman) and T. japonicum (Ashmead) for the parasitization efficiency in the laboratory. The dust formulations were prepared by impregnating the respective clay with appropriate concentration of kairomonal solutions @ $2 \mathrm{ml} \mathrm{g}^{-1}$. The slurry was thoroughly mixed, powdered using a pestle and mortar and passed through sieve (60 meshes) and dried overnight.

Tricocard as defined by Gautam (1994) treated with different formulations along with one control card (plain egg card impregnated with the solvent hexane) was arranged equidistantly in the experimental arena, which consisted of a $150 \mathrm{~mm}$ diameter glass petridish, the base of which was covered with Whatman No.1 filter paper disc of the same diameter in five replications. UV sterilized $1.0 \mathrm{~cm}^{2}$ egg cards (6 Nos.) having 30 eggs each of $C$. cephalonica (0-24 hr old) were placed equidistantly on the periphery, which formed the experimental arena (Gautam, 1994). Extracts were applied at different concentrations on five egg cards at the rate of $50 \mu \mathrm{l}$. Ten healthy, $0-24 \mathrm{hr}$ old Trichogramma females were released at the centre of each petridish. The parasitoids were allowed to search in the experimental arena for a total period of $45 \mathrm{~min}$ from the time of recovery. Number of parasitoid that visited the cards was counted at five minutes interval, which is referred as 'Parasitoid Activity Index' (PAI). After 45 minutes, the parasitoids were removed carefully from each egg card and these cards were kept individually in a glass vials for development at $25 \pm 1^{\circ} \mathrm{C}$ and $65 \pm 5 \%$ relative humidity. Data on $\mathrm{PAI}, \%$ parasitism and emergence were recorded in eight replications.

Statistical analysis : All the experiments were conducted in triplicate. The experiment was conducted on Completely Randomized Block Design as described by Padmavathi and Paul (1998) following the method by Gautam (1994). Data were presented as means \pm standard deviation and analyzed using SPSS statistical software. The ANOVA was used for comparing different treatments as described by Gomez and Gomez (1986).

\section{Results and Discussion}

Data presented in Table 1, 2 and 3 and depicted in Fig. 1 and 2 shows that combination of $\mathrm{P}_{3}+\mathrm{D}_{2}+\mathrm{T}_{2}\left(\mathrm{C}_{3}\right)$ indicated maximum value of PAI (6.19), parasitism (9.96\%) and emergence $(7.42 \%)$ with $T$. japonicum. With the same clay, T. japonicum showed minimum value of PAI (2.00) with Tricosane formulation $\left(\mathrm{C}_{5}\right)$ and minimum value of parasitism $(2.75 \%)$ and emergence $(0.88 \%)$ at control (Table 1, 2 and 3), when mean values of species and concentration were compared. Formulation of combination $P_{3}+D_{2}+T_{2}\left(C_{3}\right)$ recorded maximum mean value of $P A I$ (11.50), whereas scale extract formulation $\left(\mathrm{C}_{4}\right)$ showed maximum value of parasitism (18.88\%) and emergence (15.25\%), irrespective of the Trichogramma species studied. T. japonicum

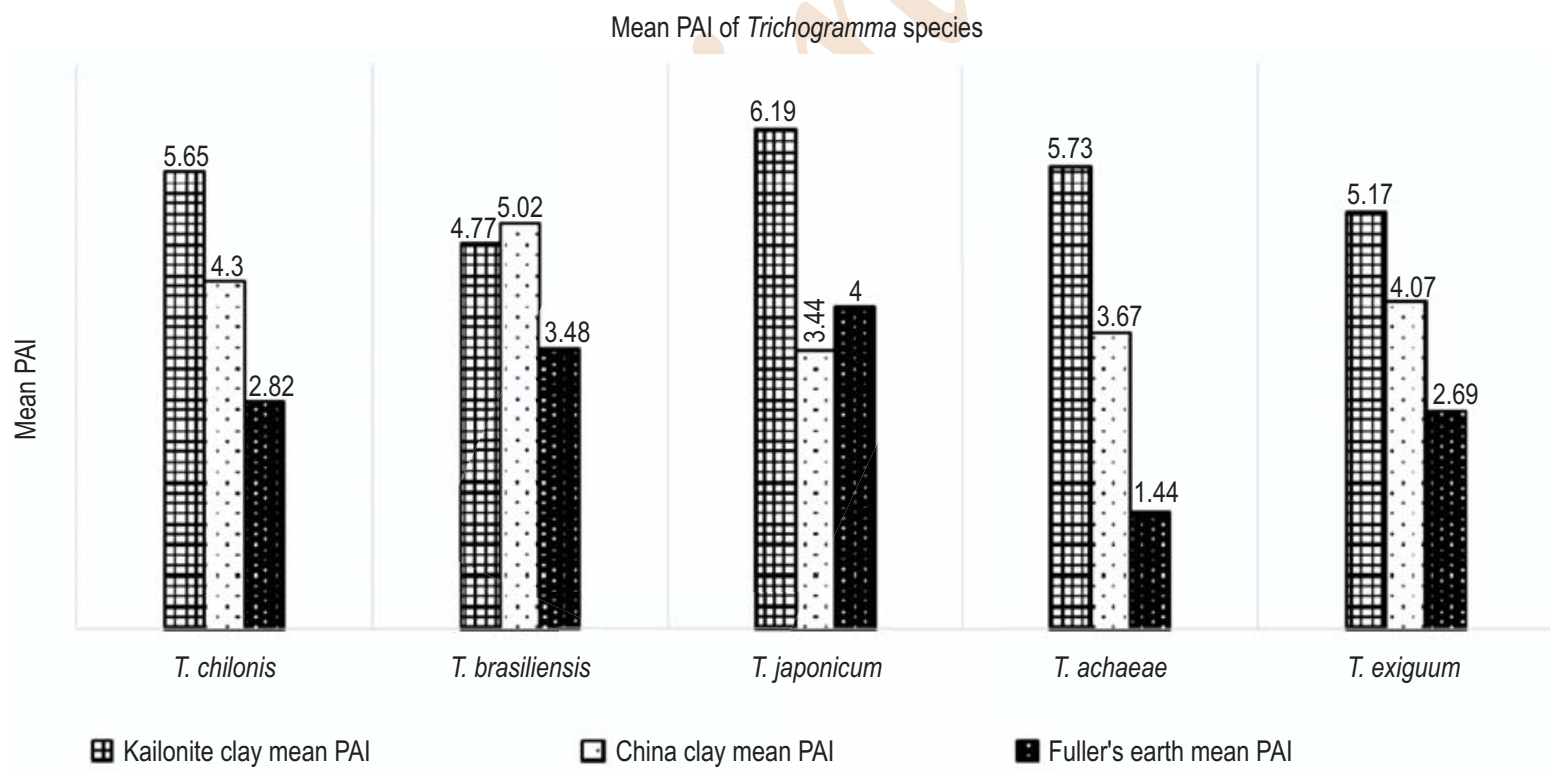

Fig. 1 : Effect of clay on parasitoid activity index (PAI) of Trichogramma spp. 
Mean parasitism of Trichogramma species

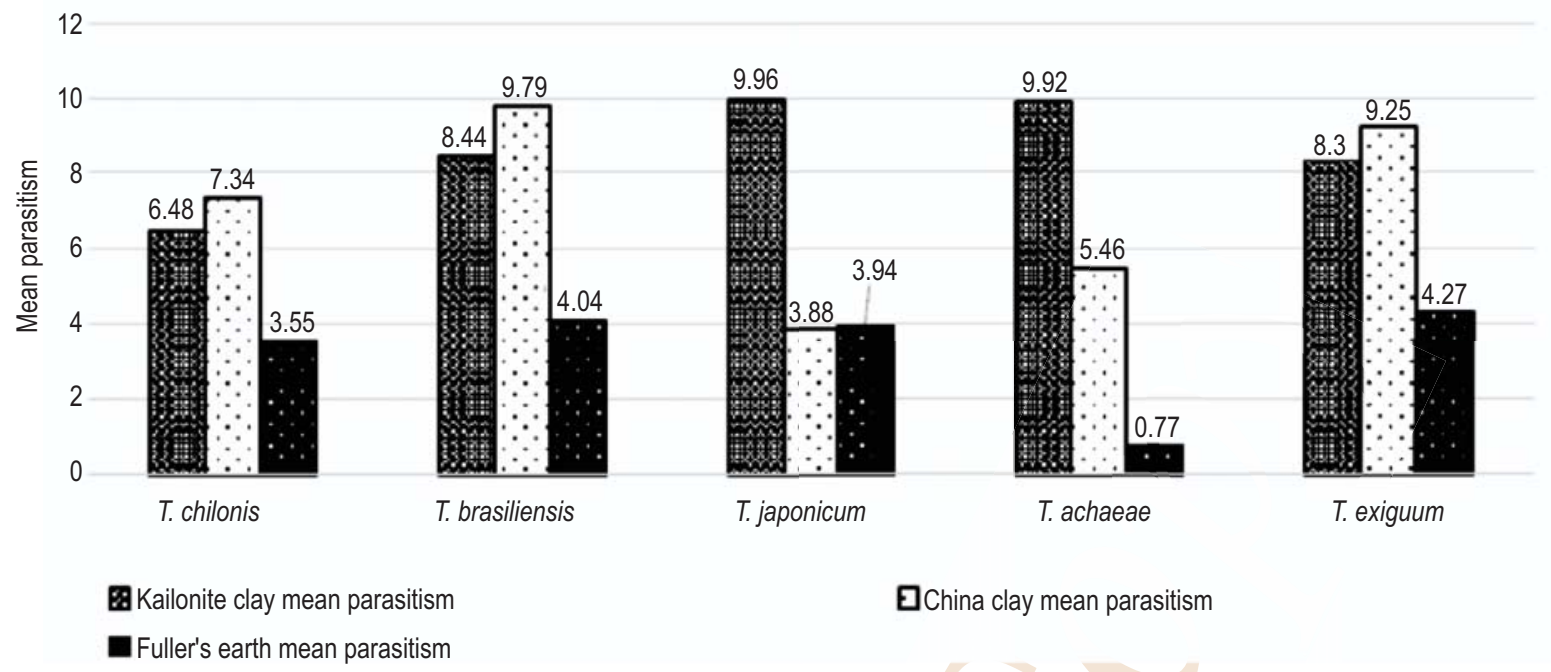

Fig. 2 : Effect of parasitism on Trichogramma spp.

elicited maximum value of PAI (6.19), parasitism (9.96\%) and emergence $(7.42 \%)$, irrespective of the combinations studied. During observing the parasitoid activity index, the values of $T$. chilonis, T. japonicum, T. achaeae and T. exiguum were significantly higher than the values of $T$. brasiliensis. In case of parasitism, T. japonicum and T. achaeae were significantly higher than T. exiguum; whereas T. brasiliensis and T. exiguum were at par with each other and the value of $T$. chilonis was significantly lower than all other species. Emergence in $T$. japonicum and $T$. exiguum was at par with each other and significantly higher than T. chilonis, T. brasiliensis and T. achaeae.

Formulation $\mathrm{P}_{3}+\mathrm{D}_{2}+\mathrm{T}_{2}\left(\mathrm{C}_{3}\right)$ of $T$. brasiliensis showed highest PAI (8.50), however highest parasitism (14.00\%) and emergence $(14.00 \%)$ was shown by scale extract formulation $\left(C_{4}\right)$ in T. exiguum. T. japonicum showed least value of PAI (1.13), parasitism $(1.13 \%)$ and emergence $(1.13 \%)$ at control $\left(\mathrm{C}_{6}\right)$. C. cephalonica scale extract $\left(\mathrm{C}_{4}\right)$ formulation recorded maximum value of PAI (6.38), however maximum parasitism (14.00\%) and emergence $(14.00 \%)$ was recorded in scale extract formulation $\left(\mathrm{C}_{4}\right)$ irrespective of the species studied. Maximum PAI (5.02), parasitism (9.79\%) and emergence $(9.79 \%)$ was recorded in $T$. brasiliensis irrespective of the formulations studied (Table 4, 5 and 6; Fig. 1 and 2).

During observing the Parasitoid Activity Index (PAI) of China clay the species T. chilonis, T. brasiliensis, T. japonicum, $T$. achaeae and $T$. exiguum were significantly higher and were at par with each other, however $T$. brasiliensis recorded significantly higher parasitism than other species. The mean parasitism values of $T$. brasiliensis and T. exiguum were also at par with each other. In case of china clay, the parasitism values of $T$. chilonis were significantly lower than the T. brasiliensis and T. exiguum; whereas the values of $T$. achaeae were still significantly lower than $T$. brasiliensis, $T$. chilonis and $T$. exiguum and the least response was shown by $T$. japonicum. Emergence of $T$. brasiliensis, T. japonicum, T. achaeae and T. exiguum was significantly higher than T. chilonis.

T. japonicum at formulation $P_{1}+D_{1}+T_{2}\left(C_{2}\right)$ showed maximum value of PAI (8.25), T. brasiliensis at Tricosane $\left(\mathrm{C}_{5}\right)$ showed maximum value of parasitism $(9.50 \%)$, whereas $T$. chilonis at Tricosane $\left(\mathrm{C}_{5}\right)$ showed maximum value of emergence (7.25\%). T. achaeae at formulation $\mathrm{P}_{2}+\mathrm{D}_{2}+\mathrm{T}_{2}\left(\mathrm{C}_{1}\right)$ showed least value of PAI (0.75) and parasitism (0.25) and T. chilonis at control showed least value of emergence $(0.13 \%)$. Formulation $P_{1}+D_{1}+T_{2}$ $\left(\mathrm{C}_{2}\right)$ in T. japonicum showed highest value of PAI (8.25); Tricosane

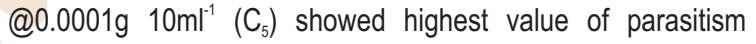
$(9.50 \%)$ in T. brasiliensis and highest value of emergence $(7.25 \%)$ in T. chilonis irrespective of the species studied (Table 7, 8 and 9; Fig. 1 and 2). During observing the response the mean Parasitoid Activity Index (PAI) of T. japonicum was significantly higher than all the other species, which were at par with each other. The mean parasitism values of T. chilonis, T. brasiliensis, T. japonicum and $T$. exiguum were significantly higher and were at par with each other than the values of $T$. achaeae, whereas the response of emergence of all the species of Trichogramma were significantly higher and were at par with each other.

Kairomonal formulations prepared with Tricosane, Docosane and Pentacosane, C. cephalonica scale extract and Tricosane at $125,250,375,10^{6}$ and $500 \mathrm{ng} \mathrm{cm}^{-2}$ respectively, in 
Table 1 : Effect of freshly prepared kairomonal dust formulation on Parasitoid Activity Index (PAI) of Trichogramma spp.

\begin{tabular}{lllllll}
\hline Parasitoid & \multicolumn{5}{c}{ Carrier used: Kailonite } \\
\cline { 2 - 7 } & $\mathbf{C}_{1}$ & $\mathbf{C}_{2}$ & $\mathbf{C}_{3}$ & $\mathbf{C}_{4}$ & $\mathbf{C}_{5}$ & $\mathbf{C}_{6}$ (Control) \\
\hline T. chilonis & $2.88^{\mathrm{c}}(1.55)$ & $3.13^{\mathrm{c}}(1.57)$ & $6.25^{\mathrm{b}}(2.05)$ & $10.63^{\mathrm{a}}(3.12)$ & $5.75^{\mathrm{b}}(2.37)$ & $5.25^{\mathrm{b}}(2.03)$ \\
T. brasiliensis & $4.38^{\mathrm{b}}(1.81)$ & $3.75^{\mathrm{b}}(1.66)$ & $4.50^{\mathrm{b}}(1.89)$ & $5.50^{\mathrm{b}}(2.09)$ & $6.88^{\mathrm{a}}(2.35)$ & $3.63^{\mathrm{c}}(1.60)$ \\
T.japonicum & $7.38^{\mathrm{c}}(2.41)$ & $4.88^{\mathrm{d}}(2.18)$ & $11.50^{\mathrm{a}}(3.01)$ & $8.75^{\mathrm{b}}(2.85)$ & $2.00^{\mathrm{a}}(1.38)$ & $2.63^{\mathrm{a}}(1.50)$ \\
T. achaeae & $6.88^{\mathrm{b}}(2.47)$ & $3.88^{\mathrm{c}}(1.57)$ & $6.00^{\mathrm{b}}(2.35)$ & $5.88^{\mathrm{b}}(2.22)$ & $7.63^{\mathrm{a}}(2.79)$ & $4.13^{\mathrm{c}}(1.88)$ \\
T. exiguum & $6.50^{\mathrm{b}}(2.12)$ & $2.13^{\mathrm{d}}(1.28)$ & $5.00^{\mathrm{c}}(1.95)$ & $6.38^{\mathrm{b}}(2.28)$ & $8.00^{\mathrm{a}}(2.51)$ & $3.00^{\mathrm{d}}(1.53)$ \\
\hline
\end{tabular}

\begin{tabular}{lll}
\hline \multicolumn{3}{l}{ Figures in parentheses are square root transformed values } \\
& $\mathrm{SE}(\mathrm{m}) \pm$ & C.D. $(0.05)$ \\
Parasitoid species & 0.40 & 1.20 \\
Conc. & 0.46 & 1.38
\end{tabular}

Table 2 : Effect of formulation of synthetic kairomones on parasitism of Trichogramma spp.

\begin{tabular}{lllllll}
\hline Parasitoid & \multicolumn{5}{c}{ Carrier used: Kailonite } \\
\cline { 2 - 7 } & C1 & C2 & C3 & C4 & C5 & C6Control \\
\hline T. chilonis & $2.88^{\mathrm{d}}(1.51)$ & $4.88^{\mathrm{cb}}(1.76)$ & $4.75^{\mathrm{d}}(1.62)$ & $14.75^{\mathrm{b}}(3.66)$ & $6.25^{\mathrm{d}}(2.25)$ & $5.38^{\mathrm{a}}(1.94)$ \\
T. brasiliensis & $7.38^{\circ}(2.29)$ & $6.88^{\mathrm{b}}(2.07)$ & $10.75^{\mathrm{b}}(2.70)$ & $9.88^{\mathrm{d}}(2.74)$ & $11.88^{\circ}(3.01)$ & $3.88^{\mathrm{a}}(1.67)$ \\
T.japonicum & $10.50^{\mathrm{ab}}(2.86)$ & $9.88^{\mathrm{a}}(2.85)$ & $12.50^{\mathrm{a}}(3.07)$ & $18.88^{\mathrm{a}}(3.97)$ & $5.25^{\mathrm{d}}(1.86)$ & $2.75^{\mathrm{c}}(1.54)$ \\
T. achaeae & $12.13^{\mathrm{a}}(3.12)$ & $5.75^{\mathrm{b}}(1.82)$ & $11.88^{\mathrm{a}}(3.09)$ & $11.00^{\mathrm{c}}(2.91)$ & $15.38^{\mathrm{a}}(3.82)$ & $3.38^{\mathrm{c}}(1.67)$ \\
T. exiguum & $8.13^{\mathrm{bc}}(2.34)$ & $2.88^{\mathrm{d}}(1.40)$ & $8.25^{\mathrm{c}}(2.40)$ & $13.63^{\mathrm{bc}}(3.20)$ & $12.88^{\mathrm{b}}(3.11)$ & $4.00^{\mathrm{abc}}(1.69)$ \\
\hline
\end{tabular}

\begin{tabular}{lll}
\hline \multicolumn{3}{l}{ Figures in parentheses are square root transformed values } \\
& $\mathrm{SE}(\mathrm{m}) \pm$ & $\mathrm{C} . \mathrm{D} .(0.05)$ \\
Parasitoid species & 0.60 & 1.77 \\
Conc. & 0.68 & 1.98
\end{tabular}

$\begin{array}{lll}\text { Conc. } & 0.68 & 1.98\end{array}$

Table 3: Effect of formulation of synthetic kairomones on emergence of Trichogramma spp.

\begin{tabular}{llllllll}
\hline Parasitoid & \multicolumn{9}{c}{ Carrier used: Kailonite } & & Mean \\
\cline { 2 - 8 } & $\mathbf{C}_{1}$ & $\mathbf{C}_{2}$ & $\mathbf{C}_{3}$ & $\mathbf{C}_{4}$ & $\mathbf{C}_{5}$ & $\mathbf{C}_{6}$ Control \\
\hline T.chilonis & $10.25^{\mathrm{a}}(2.63)$ & $10.63^{\mathrm{a}}(2.67)$ & $5.88^{\mathrm{bc}}(1.75)$ & $7.63^{\mathrm{bc}}(2.14)$ & $8.25^{\mathrm{bc}}(2.22)$ & $1.38^{\mathrm{ab}}(1.04)$ & $7.34^{\mathrm{b}}(2.12)$ \\
T.brasiliensis & $3.88^{\mathrm{c}}(1.74)$ & $2.75^{\mathrm{c}}(1.38)$ & $3.25^{\mathrm{c}}(1.62)$ & $5.25^{\mathrm{b}}(1.86)$ & $7.00^{\mathrm{a}}(2.17)$ & $1.13^{\mathrm{d}}(1.00)$ & $5.46^{\mathrm{b}}(1.93)$ \\
T.japonicum & $9.25^{\mathrm{b}}(2.32)$ & $9.75^{\mathrm{b}}(2.37)$ & $10.63^{\mathrm{b}}(2.67)$ & $13.00^{\mathrm{a}}(2.92)$ & $12.88^{\mathrm{a}}(2.91)$ & $3.25^{\mathrm{d}}(1.50)$ & $9.79^{\mathrm{a}}(2.45)$ \\
T.achaeae & $4.88^{\mathrm{c}}(1.81)$ & $5.13^{\mathrm{b}}(1.85)$ & $8.75^{\mathrm{a}}(2.47)$ & $7.13^{\mathrm{b}}(2.23)$ & $5.38^{\mathrm{c}}(2.02)$ & $1.50^{\mathrm{d}}(1.20)$ & $3.88^{\mathrm{b}}(1.63)$ \\
T.exiguum & $11.13^{\mathrm{b}}(2.74)$ & $6.88^{\mathrm{d}}(2.07)$ & $9.38^{\mathrm{c}}(2.34)$ & $14.00^{\mathrm{a}}(3.25)$ & $12.00^{\mathrm{b}}(2.82)$ & $2.13^{\mathrm{a}}(1.14)$ & $9.25^{\mathrm{a}}(2.39)$ \\
\hline
\end{tabular}

Figures in parentheses are square root transformed values

$\begin{array}{lll} & \text { SE }(m) \pm & \text { C.D. }(0.05) \\ \text { Parasitoid species } 0.39 & 1.17 & \end{array}$

$\begin{array}{lll}\text { Concentration } & 0.47 & 1.41\end{array}$

five different concentrations showed significant variations. Kailonite clay showed the maximum value of PAI (6.19), parasitism $(9.96 \%)$ in $T$. japonicum and maximum value of emergence (9.79\%) in T. brasiliensis when formulations from all the three clays were compared. These findings are in agreement with Bakthavatsalam and Tondon (2006) who reported that kairomonal compounds present in C. cephalonica moth scales fortified with Nonacosane $(0.3 \%)$, Hexacosane $(0.3 \%)$, Pentacosane $(0.2 \%)$ and Tricosane $(0.3 \%)$ increased significantly the egg parasitism efficiency of T. chilonis. Boo and
Yang (2000) made similar observations on the effect of male moth scale extract of $H$. assulta on increasing efficiency of $T$. chilonis and reported that the extract contained fractions of saturated hydrocarbons. The dust formulations can be more effective in integrated pest management programmes because of their unique mode of release in field conditions. The choice of formulation type can have an adverse impact on human health and the environment. These studies have demonstrated the utility of formulations in chemical communications and indicated the importance of formulation performance on efficacy. Therefore, 
Table 4 : Effect of freshly prepared kairomonal dust formulation on Parasitoid Activity Index of Trichogramma spp.

\begin{tabular}{lllllll}
\hline Parasitoid & \multicolumn{5}{c}{ Carrier used: China clay } \\
\cline { 2 - 7 } & $\mathbf{C}_{1}$ & $\mathbf{C}_{2}$ & $\mathbf{C}_{3}$ & $\mathbf{C}_{4}$ & $\mathbf{C}_{5}$ & $\mathbf{C}_{6}$ (Control) \\
\hline T. chilonis & $5.13^{\mathrm{a}}(1.96)$ & $5.50^{\mathrm{a}}(2.03)$ & $3.38^{\mathrm{bc}}(1.45)$ & $4.25^{\mathrm{ab}}(1.71)$ & $5.63^{\mathrm{a}}(1.90)$ & $1.88^{\mathrm{c}}(1.23)$ \\
T. brasiliensis & $3.75^{\mathrm{b}}(1.70)$ & $5.00^{\mathrm{b}}(1.83)$ & $8.50^{\mathrm{a}}(2.26)$ & $6.00^{\mathrm{b}}(2.11)$ & $4.88^{\mathrm{b}}(1.94)$ & $2.00^{\mathrm{b} c}(1.34)$ \\
T.japonicum & $3.50^{\circ}(1.71)$ & $2.25^{\mathrm{c}}(1.30)$ & $3.38^{\mathrm{ab}}(1.74)$ & $4.75^{\mathrm{a}}(1.89)$ & $5.63^{\mathrm{a}}(2.03)$ & $1.13^{\mathrm{d}}(1.00)$ \\
T. achaeae & $3.13^{\mathrm{b}}(1.54)$ & $3.00^{\mathrm{b}}(1.51)$ & $4.75^{\mathrm{a}}(1.90)$ & $5.13^{\mathrm{a}}(1.95)$ & $4.13^{\mathrm{a}}(1.82)$ & $1.88^{\mathrm{c}}(1.31)$ \\
T. exiguum & $4.25^{\mathrm{b}}(1.90)$ & $2.88^{\mathrm{b}}(1.51)$ & $3.25^{\mathrm{b}}(1.58)$ & $6.38^{\mathrm{a}}(2.28)$ & $6.38^{\mathrm{a}}(2.14)$ & $1.25^{\mathrm{c}}(1.07)$ \\
\hline
\end{tabular}

Figures in parentheses are square root transformed values

SE $(m)+\quad$ C.D. $(0.05)$

$\begin{array}{lll} & & \\ \text { Conc } & & 1.86 \\ & 0.71 & 2.13\end{array}$

Table 5 : Effect of formulation of synthetic kairomones on parasitism of Trichogramma spp.

\begin{tabular}{lllllll}
\hline Parasitoid & \multicolumn{5}{c}{ Carrier used: China clay } \\
\cline { 2 - 7 } & $\mathbf{C}_{1}$ & $\mathbf{C}_{2}$ & $\mathbf{C}_{3}$ & $\mathbf{C}_{4}$ & $\mathbf{C}_{5}$ & $\mathbf{C}_{6}$ (Control) \\
\hline T. chilonis & $10.25^{\mathrm{a}}(2.63)$ & $10.63^{\mathrm{a}}(2.67)$ & $5.88^{\mathrm{bc}}(1.75)$ & $7.63^{\mathrm{bc}}(2.14)$ & $8.25^{\mathrm{bc}}(2.22)$ & $1.38^{\mathrm{ab}}(1.04)$ \\
T. brasiliensis & $9.25^{\mathrm{ab}}(2.32)$ & $9.75^{\mathrm{a}}(2.37)$ & $10.63^{\mathrm{a}}(2.67)$ & $13.00^{\mathrm{a}}(2.92)$ & $12.88^{\mathrm{a}}(2.91)$ & $3.25^{\mathrm{a}}(1.50)$ \\
T.japonicum & $3.88^{\mathrm{c}}(1.74)$ & $2.75^{\mathrm{C}}(1.38)$ & $3.25^{\mathrm{c}}(1.62)$ & $5.25^{\mathrm{c}}(1.86)$ & $7.00^{\mathrm{c}}(2.17)$ & $1.13^{\mathrm{ba}}(1.00)$ \\
T. achaeae & $4.88^{\mathrm{c}}(1.81)$ & $5.13^{\mathrm{b}}(1.85)$ & $8.75^{\mathrm{ab}}(2.47)$ & $7.13^{\mathrm{b}}(2.23)$ & $5.38^{\mathrm{c}}(2.02)$ & $1.50^{\mathrm{ab}}(1.20)$ \\
T. exiguum & $11.13^{\mathrm{a}}(2.74)$ & $6.88^{\mathrm{b}}(2.07)$ & $9.38^{\mathrm{ab}}(2.34)$ & $14.00^{\mathrm{a}}(3.25)$ & $12.00^{\mathrm{a}}(2.82)$ & $2.13^{\mathrm{ab}}(1.14)$ \\
\hline
\end{tabular}

Figures in parentheses are square root transformed values

$\begin{array}{lll} & \mathrm{SE}(\mathrm{m}) \pm & \text { C.D. } \\ \text { Parasitoid species } & 0.73 & 2.09 \\ \text { Conc. } & 0.81 & 2.27\end{array}$

Table 6: Effect of freshly prepared kairomonal dust formulation on emergence of Trichogramma spp.

\begin{tabular}{llllllll}
\hline Parasitoid & \multicolumn{5}{c}{ Carrier used: China clay } & $\mathbf{C}_{6}$ (Control) & Mean \\
\cline { 2 - 7 } & $\mathbf{C}_{1}$ & $\mathbf{C}_{2}$ & $\mathbf{C}_{3}$ & $\mathbf{C}_{4}$ & $\mathbf{C}_{5}$ & \\
\hline T. chilonis & $2.25^{\mathrm{c}}(1.39)$ & $3.88^{\mathrm{b}}(1.62)$ & $3.75^{\mathrm{b}}(1.51)$ & $11.00^{\mathrm{a}}(3.17)$ & $4.88^{\mathrm{b}}(2.03)$ & $4.63^{\mathrm{b}}(1.82)$ & $5.15^{\mathrm{b}}(1.92)$ \\
T. brasiliensis & $5.50^{\mathrm{c}}(2.03)$ & $4.38^{\mathrm{c}}(1.75)$ & $7.75^{\mathrm{b}}(2.35)$ & $8.13^{\mathrm{b}}(2.51)$ & $10.00^{\mathrm{a}}(2.79)$ & $2.50^{\mathrm{d}}(1.45)$ & $6.38^{\mathrm{a}}(2.15)$ \\
T.japonicum & $8.25^{\mathrm{c}}(2.57)$ & $6.75^{\mathrm{d}}(2.29)$ & $9.88^{\mathrm{b}}(2.75)$ & $15.25^{\mathrm{a}}(3.60)$ & $3.50^{\mathrm{a}}(1.60)$ & $0.88^{\mathrm{f}}(1.03)$ & $7.42^{\mathrm{a}}(2.31)$ \\
T. achaeae & $9.25^{\mathrm{a}}(2.69)$ & $4.50^{\mathrm{c}}(1.61)$ & $9.88^{\mathrm{a}}(2.76)$ & $7.88^{\mathrm{b}}(2.50)$ & $10.00^{\mathrm{a}}(2.79)$ & $1.50^{\mathrm{d}}(1.22)$ & $7.17^{\mathrm{a}}(2.26)$ \\
T. exiguum & $5.88^{\mathrm{b}^{\prime}(2.06)}$ & $2.50^{\mathrm{c}}(1.34)$ & $6.25^{\mathrm{b}}(2.13)$ & $10.50^{\mathrm{a}}(2.84)$ & $10.88^{\mathrm{a}}(2.88)$ & $3.38^{\circ}(1.59)$ & $6.57^{\mathrm{a}}(2.14)$ \\
\hline
\end{tabular}

Figures in parentheses are square root transformed values

$\begin{array}{lll} & \mathrm{SE}(\mathrm{m}) \pm & \text { C.D. }(0.05) \\ \text { Parasitoid species } 0.49 & 1.47 & \\ \text { Conc. } & 0.57 & 1.71\end{array}$

these formulations have been found effective in chemical communications using kairomones and synomones and can withstand wide fluctuations in temperature, rainfall and humidity. The present studies were carried out to identify effective kairomonal compound, optimum concentration and appropriate application technique to increase the parasitizing efficiency of $T$. chilonis. Yadav and Paul (2009) explained the effect of host eggs and scale formulations of $C$. cephalonica on the searching ability in relation to the distance moved by T. exiguum. They found that maximum mean parasitism percentage was observed on treatment with unwashed eggs and Corcyra scale dust formulations, followed by hexane washed eggs and Corcyra scale. Effect of kairomones on Trichogramma has been studied by different workers. Paul et al. (2008) described the semiochemicals produced by 10 different varieties of tomato obtained in the vegetative and flowering period for their 
Table 7 : Effect of freshly prepared kairomonal dust formulation on Parasitoid Activity Index of Trichogramma spp.

\begin{tabular}{lllllll}
\hline Parasitoid & \multicolumn{5}{c}{ Carrier used: Fuller's earth } \\
\cline { 2 - 7 } & $\mathbf{C}_{1}$ & $\mathbf{C}_{2}$ & $\mathbf{C}_{3}$ & $\mathbf{C}_{4}$ & $\mathbf{C}_{5}$ & $\mathbf{C}_{6}$ (Control) \\
\hline T. chilonis & $2.63^{\mathrm{b}}(1.57)$ & $3.00^{\mathrm{b}}(1.53)$ & $2.13^{\mathrm{b}}(1.51)$ & $3.63^{\mathrm{a}}(1.61)$ & $4.25^{\mathrm{a}}(1.89)$ & $1.25^{\mathrm{d}}(1.09)$ \\
T. brasiliensis & $4.63^{\mathrm{b}}(1.94)$ & $3.25^{\mathrm{c}}(1.62)$ & $2.13^{\mathrm{d}}(1.28)$ & $2.25^{\mathrm{d}}(1.30)$ & $6.00^{\mathrm{a}}(2.24)$ & $2.63^{\mathrm{c}}(1.60)$ \\
T.japonicum & $4.00^{\circ}(1.80)$ & $8.25^{\circ}(2.35)$ & $5.75^{\mathrm{b}}(2.28)$ & $1.25^{\mathrm{o}}(1.07)$ & $2.88^{\mathrm{d}}(1.59)$ & $1.88^{\mathrm{d}}(1.16)$ \\
T. achaeae & $0.75^{\circ}(1.01)$ & $1.50^{\mathrm{b}}(1.26)$ & $3.25^{\mathrm{a}}(1.83)$ & $0.75^{\mathrm{c}}(1.03)$ & $1.50^{\mathrm{b}}(1.22)$ & $0.88^{\mathrm{c}}(0.96)$ \\
T. exiguum & $2.25^{\circ}(1.30)$ & $1.88^{\mathrm{c}}(1.27)$ & $1.38^{\mathrm{d}}(1.14)$ & $3.50^{\mathrm{a}}(1.72)$ & $4.25^{\mathrm{a}}(1.71)$ & $2.88^{\mathrm{b}}(1.56)$ \\
\hline
\end{tabular}

Figures in parentheses are square root transformed values

SE $(m)+\quad$ C.D. $(0.05)$

$\begin{array}{lll} & 1.02 \\ & 0.34 & 1.17\end{array}$

Table 8: Effect of formulation of kairomones on parasitism of Trichogramma spp.

\begin{tabular}{lllllll}
\hline Parasitoid & \multicolumn{5}{c}{ Carrier used: Fuller's earth } \\
\cline { 2 - 7 } & $\mathbf{C}_{1}$ & $\mathbf{C}_{2}$ & $\mathbf{C}_{3}$ & $\mathbf{C}_{4}$ & $\mathbf{C}_{5}$ & $\mathbf{C}_{6}$ (Control) \\
\hline T. chilonis & $2.00^{\mathrm{b}}(1.39)$ & $2.63^{\mathrm{bc}}(1.33)$ & $2.63^{\mathrm{b}}(1.46)$ & $5.13^{\mathrm{b}}(1.85)$ & $8.38^{\mathrm{a}}(2.42)$ & $0.50^{\mathrm{b}}(0.88)$ \\
T. brasiliensis & $5.25^{\mathrm{a}}(1.95)$ & $2.75^{\mathrm{b}}(1.36)$ & $2.25^{\mathrm{b}}(1.30)$ & $2.75^{\mathrm{c}}(1.38)$ & $9.50^{\mathrm{a}}(2.66)$ & $1.75^{\mathrm{ab}}(1.19)$ \\
T.japonicum & $4.50^{\mathrm{b}}(1.87)$ & $7.50^{\mathrm{a}}(2.38)$ & $7.75^{\mathrm{a}}(2.50)$ & $0.88^{\mathrm{d}}(0.96)$ & $1.75^{\mathrm{d}}(1.17)$ & $1.25^{\mathrm{b}}(1.02)$ \\
T. achaeae & $0.25^{\mathrm{c}}(0.82)$ & $1.25^{\mathrm{c}}(1.14)$ & $1.50^{\mathrm{c}}(1.23)$ & $0.25^{\mathrm{d}}(0.82)$ & $0.88^{\mathrm{d}}(1.03)$ & $0.50^{\mathrm{b}}(0.88)$ \\
T. exiguum & $4.38^{\mathrm{ab}}(1.59)$ & $2.88^{\mathrm{b}}(1.39)$ & $2.25^{\mathrm{b}}(1.30)$ & $6.63^{\mathrm{a}}(2.20)$ & $7.00^{\mathrm{b}}(2.08)$ & $2.50^{\mathrm{a}}(1.41)$ \\
\hline
\end{tabular}

Figures in parentheses are square root transformed values

SE $(\mathrm{m}) \pm \quad$ C.D. $(0.05)$

Conc $\quad 0.58-1.42$

Table 9 : Effect of freshly prepared kairomonal dust formulation on emergence of Trichogramma spp.

\begin{tabular}{|c|c|c|c|c|c|c|c|}
\hline \multirow[t]{2}{*}{ Parasitoid } & \multicolumn{6}{|c|}{ Kairomonal dust formulation-Carrier used: Fuller's earth } & \multirow[t]{2}{*}{ Mean } \\
\hline & $\mathrm{C}_{1}$ & $\mathrm{C}_{2}$ & $\mathrm{C}_{3}$ & $\mathrm{C}_{4}$ & $\mathrm{C}_{5}$ & $\mathrm{C}_{6}$ (Control) & \\
\hline T. chilonis & $1.25^{\circ}(1.18)$ & $2.00^{c}(1.13)$ & $2.00^{\circ}(1.33)$ & $4.38^{\mathrm{b}}(1.74)$ & $7.25^{\mathrm{a}}(2.28)$ & $0.13^{\circ}(0.77)$ & $2.84^{\mathrm{a}}(1.41)$ \\
\hline T. brasiliensis & $3.25^{\mathrm{a}}(1.54)$ & $1.88^{\mathrm{c}}(1.22)$ & $1.75^{\circ}(1.20)$ & $2.50^{b}(1.34)$ & $4.50^{\mathrm{a}}(1.88)$ & $1.38^{\circ}(1.11)$ & $2.54^{\mathrm{a}}(1.38)$ \\
\hline T. japonicum & $4.13^{\mathrm{a}}(1.81)$ & $5.38^{\mathrm{a}}(2.07)$ & $4.25^{\mathrm{a}}(1.83)$ & $0.50^{b}(0.88)$ & $1.38^{b}(1.04)$ & $1.13^{b}(1.00)$ & $2.80^{\mathrm{a}}(1.44)$ \\
\hline T. achaeae & $1.50^{\mathrm{b}}(1.23)$ & $1.88^{\mathrm{a}}(1.16)$ & $2.00^{\mathrm{a}}(1.34)$ & $2.25^{\mathrm{a}}(1.30)$ & $2.88^{\mathrm{a}}(1.56)$ & $1.25^{\mathrm{b}}(1.09)$ & $1.96^{\mathrm{a}}(1.28)$ \\
\hline T. exiguum & $3.50^{\mathrm{b}}(1.48)$ & $1.88^{\mathrm{c}}(1.23)$ & $1.63^{\mathrm{c}}(1.18)$ & $5.63^{\mathrm{a}}(2.05)$ & $5.25^{\mathrm{a}}(1.86)$ & $1.63^{\circ}(1.18)$ & $3.90^{\mathrm{a}}(1.50)$ \\
\hline
\end{tabular}

Figures in parentheses are square root transformed values

SE $(\mathrm{m}) \pm \quad$ C.D. $(0.05)$

Parasitoid species $\quad 0.45 \quad 1.34$

$\begin{array}{lll}\text { Conc. } & 0.52 & 1.56\end{array}$

synomonal response and observed higher response in the flowering period, which could be due to presence of higher relative quantities of tricosane, heneicosane and hexacosane. Srivastava et al. (2008) compared the kairomonal response of the three host insects viz., S. litura, S. exigua and C. auricilius in both male and female and concluded that the response elicited by the male extract body of $S$. litura was significantly higher, whereas the extract body of male $C$. auricilius elicited least response from $T$. chilonis. Srivastava and Singh (2009) observed that among the seven organic acids (triacontanoic, docosanoic, octosanoic, tricosanoic, pentadeconoic, heptacosanoic and hexacosanoic acid); triacontanoic acid elicited the highest response from $T$. chilonis, followed by docosanoic and octocosanoic acids. Sharma and Aggarwal (2015) evaluated the dispersal ability and parasitisation performance of Trichogramma spp in organic Basmati rice. It was found that among the two parasitoid species, T. chilonis showed higher parasitism in different distance treatments in comparison to T. japonicum. 
Natural enemies including egg parasitoid like Trichogrammatids respond towards chemical cues present in the environment to locate their hosts. Many a times these cues are associated with host and host byproducts itself. The present study, revealed that the emission rate of synthetic kairomone was fastest from kailonite clay as compared to china clay and fuller's earth in a given limit of time. Therefore, in the present study $T$. brasiliensis and $T$. japonicum with kairomonal formulation (Tricosane @0.0001 g 10 $\mathrm{ml}^{-1}$ ) and kailonite clay could be recommended for the integrated pest management programme.

\section{Acknowledgments}

The authors are thankful to the Head, Division of Entomology, Indian Agricultural Research Institute, New Delhi for the facilities provided. The financial assistance provided to the senior author by the Indian Council of Agricultural Research, New Delhi is thankfully acknowledged.

\section{References}

Bakthavatsalam, N. and P.L. Tondon: Kairomones, their optimum concentrations and application techniques to enhance the parasitization efficiency of Trichogramma chilonis Ishii. (Hymenoptera:Trichogrammatidae) J. Bio. Cont., 20, 169-174 (2006).

Balakrishnan, N., R.K.M. Baskaran and N.R. Mahadevan: Efficacy of Trichogramma chilonis Ishii in combination with biopesticides against Helicoverpa armigera (Hubner) in rain fed cotton ecosystem. J. Biol. Cont., 18, 121-127 (2004).

Boo, K.S. and J.P. Yang: Kairomones used by Trichogramma chilonis to find Helicoverpa assulta eggs. J. Chem. Ecol., 26, 359-375 (2000).

Colazza, S., A. Cusumano, D. Lo. Giuduce and E. Peri: Chemoorientation responses in Hymenopteran parasitoids induced by substrate-borne semiochemicals. Biocontrol, 59, 1-17 (2004).

Colazza, S., E. Peri, G. Salernoand E. Conti: Host searching by egg parasitoids: Exploitation of host chemical cues. In: Egg parasitoids in Agroecosystems with emphasis on Trichogramma (Eds.: F. L. Consoli, J. R. P. Parra and R. A. Zucchi). Progress in Biological Control, pp 97-147 (2010).

Caro, J.H., H.P. Freeman, D.L. Brower and B.A. Bierl-Leonhardt: Comparative distribution and persistence of disparlure in woodland air after aerial application of three controlled release formulations. J. Chem. Ecol., 7, 867-880 (1981).

Fatouros, N.E., M. Dicke, R. Mumm and M. Hilker: Foraging behaviour of egg parasitoids exploiting chemical information. Behav. Ecol.,19, 677-689 (2008).
Gautam, R.D.: Biological Pest Suppression (Revised and enlarged in 2008), Westville Publishing House, Delhi, p. 304. (1994).

Gomez, K.A and A.A. Gomez: Statistical procedures for agricultural research. $2^{\text {nd }}$ Edn., John Wiley and Sons, New York, p. 657 (1986).

Jackson, D.M., K.A. Sorensen, C.E. Sorenson and R.N. Story: Monitoring cucumber beetle in sweet potato and cucurbits with kairomone-baited Traps. J. Econ. Entomol., 98, 159-170 (2005).

Padmavathi, Ch. and A.V.N. Paul: Saturated hydrocarbons as kairomonal source for the egg parasitoid, Trichogramma chilonis Ishii (Hym. Trichogrammatidae). J. Appl. Entomol., 122, 29-32 (1998).

Paul, A.V.N. and K.M. Sreekumar: Improved technology for mass rearing of Trichogrammatids and their factitious host Corcyra cephalonica St. in Technology in Biological control. Oxford \& IBH Pub. Co. Pvt. Ltd., New Delhi, pp. 99-111 (1998).

Paul, A.V.N., M. Srivastava, P. Dureja and A.K. Singh: Semiochemicals produced by tomato varieties and their role in parasitism of Corcyra cephalonica (Lepidoptera: Pyralidae) by the egg parasitoid Trichogramma chilonis (Hymenoptera: Trichogrammatidae). Int. J. Trop. Insect Sci., 28, 108-116 (2008).

Rahman, S.J., A.G. Rao and P.S. Reddy: Potential and economics of bio intensive insect pest management (BIPM) module in cotton for sustainable production. In: Biological control of Lepidopteron pests (Eds.: P.L. Tandon, C.R. Ballal, S.K. Jalali and R.J. Rabindra). Society for Biocontrol Advancement, Bangalore, pp. 279-283 (2003).

Renou, M., P. Nagnan, A. Bertheir and C. Durier: Identification of compounds from the eggs of Ostrinia nubilalis and Mamestra brassicae having kairomone activity on Trichogramma brassicae. Entomol. Exp. Appl., 63, 291-303 (1992).

Sharma, S. and N. Aggarwal: Dispersal ability and parasitisation performance of Trichogramma spp. (Hymenoptera: Trichogrammatidae) in organic Basmati rice. J. Environ. Biol., 36, 1345-1348 (2015).

Srivastava, M. and A.K. Singh: Kairomonal effect of certain organic acids on the egg parasitoid, Trichogramma chilonis Ishii (Hymenoptera: Trichogrammatidae). J. Biol. Cont., 23, 361-364(2009).

Srivastava, M., A.V.N. Paul, P. Dureja and A.K.Singh: Response of the egg parasitoid Trichogramma chilonis Ishii (Hymenoptera: Trichogrammatidae) to kairomones from three host insects. J. Biol. Control., 22, 333-340(2008).

Tondon P.L.: Kairomones In: Potential in enhancing the efficiency of parasitoids and predators in different crop ecosystems. Proceedings of the symposium on Biocontrol Based Pest Management for Quality Crop Protection in the Current Millennium, pp.36-40 (2001).

Yadav, B. and A.V.N. Paul: Kairomonal effect of Corcyra cephalonica scale dust formulation on searching ability of Trichogramma exiguum. Ann. PlantProtec. Sci., 17, 459-460 (2009). 